\title{
Dipeptidyl Peptidase-4 Activity Measurement
}

National Cancer Institute

\section{Source}

National Cancer Institute. Dipeptidyl Peptidase-4 Activity Measurement. NCI Thesaurus.

Code C103387.

The determination of the amount of the biological activity of dipeptidyl peptidase- 4 in a sample. 